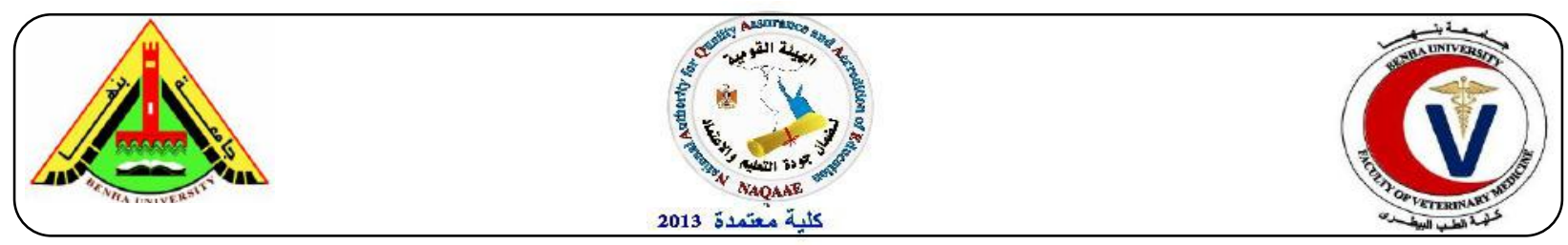

\title{
Ameliorative Effects of Curcumin and Ginger on Hyperlipidemia - Induced Osmotic Fragility and Phospholipids Composition Changes of Erythrocytes in
} Albino Rats

\author{
Shaimaa I. El-Barbary, Mohamed E. Azab, Randa S. Ismail, Abeer A. Nafeaa* \\ Department of Physiology, Faculty of Veterinary Medicine, Benha University, Egypt
}

\section{$\underline{\text { A B S T R A C T }}$}

The present study was designed to investigate the erythrocytic changes caused by hyperlipidemia in rats and to evaluate the possible protective effects of curcumin and ginger supplementation. Forty male albino rats were assigned into four equal groups. Group I (control group), rats were fed basal diet. Group II (high-fat diet, HFD group), rats were fed HFD. Group III (curcumin supplemented HFD group), rats were fed HFD contain $0.2 \%$ curcumin. Group IV (ginger supplemented HFD group), rats were fed HFD contain $4 \%$ ginger. After 2 months, blood samples were collected from retroorbital venous plexus for determination of osmotic fragility of erythrocytes, membrane phospholipids composition and serum lipid profiles. The obtained results revealed that feeding HFD to rats significantly increased serum TC, TAG, LDL-C and phospholipid (phosphatidyl choline, phosphatidyl serine, phosphatidyl ethanolamine and phosphatidyl inositol) concentrations and significantly decreased hemolysis $\%$ at 0.4 and $0.5 \% \mathrm{Na} \mathrm{Cl}$ concentrations as compared with control group. Whereas these changes ameliorated by dietary supplementation of curcumin and ginger as feeding HFD supplemented with $0.2 \%$ curcumin or $4 \%$ ginger significantly decreased TC, TAG, LDL-C and phospholipid concentrations and significantly increased hemolysis $\%$ at 0.4 and $0.5 \% \mathrm{Na} \mathrm{Cl}$ concentrations as compared with high fat diet fed group. We concluded that supplementation with ginger and curcumin to HFD rats resulted in a significant decrease in serum lipid concentration, lowering membrane phospholipid and beneficially decreased mean cell fragility of erythrocytes thus restored the normality of erythrocyte fluidity in high fat diet fed rats. Key words: Hyperlipidemia, erythrocyte osmotic fragility, membrane phospholipids, curcumin and ginger.

*Corresponding author: abeernafeaa1973@gmail.com

(http://www.bvmj.bu.edu.eg)

(bvmj, 35(1): : 327-341, Sept., 2018)

\section{INTRODUCTION:}

Red blood cells (RBCs) comprise 40$45 \%$ of total blood volume (Badior and Casey, 2018). The main function of the RBCs is to provide tissue with oxygen and remove carbon dioxide and protons produced in metabolic processes (Andrzej et al., 2002). RBCs membrane consists of $52 \%$ proteins and $40 \%$ lipids including cholesterol (Himbert et al., 2017). Because erythrocytes have no endogenous synthesis of lipids, their membrane lipids composition better reflects plasma lipids than that of vascular or endothelial cells (Zicha et al., 1999).

Membrane phospholipids differ in the headgroups and hydrocarbon chains (Barenholz, 2002). Their polar headgroups may be choline, ethanol amine, serine, 
inositol, inositol phosphates or glycerol (Koay and Walmsle, 1999). The choline- containing phospholipid phosphatidylcholine (PC) is the most abundant type in animal cell membranes, and phosphatidylethanolamine (PE) is the second most (Williams, 1998), with sphingomyelin (SM) also contributing significantly to the membrane phospholipid composition (Barenholz and Thompson, 1999). Phospholipids PC and SM are contained on the outer leaflet of cell membrane, while PE and phosphatidylserine (PS) are on the inside (Koay and Walmsley 1999). PE phospholipids are orderedcrystalline- phase lipids and can pack closely in membranes, while PC phospholipids are liquid- crystalline- phase lipids and do not pack close in the membrane (Hamai et al., 2006). A combination of both phases is needed in cell membranes to regulate membrane fluidity.

Micro organisms adjust the order, or fluidity, of their cell membranes in response to changes in their physiochemical environment (Hazel and Williams 1990; Williams 1998; Barenholz 2002). They do this by changing the membrane lipid composition (Allen et al., 2006). Membrane lipid changes can also result in changes in RBC membrane fluidity and deformability, which is important to these cells when passing through small capillaries. Changes in RBC membrane deformability could compromise oxygen delivery and could therefore contribute to disease outcome. RBC deformability correlates with the phospholipid PE to PS ratio (Allen et al., 2006). Maintaining a balanced degree of membrane fluidity is important to RBCs because these cells are vulnerable to hydrolysis by serum phospholipase A2 (sPLA2) and a target for prostaglandin action with diminished fluidity and deformability (Harris et al., 2001).
During the past three decades, several beneficial physiological effects of spices (that are consumed mainly as food adjuncts to enhance sensory quality of foods) have been experimentally documented such as their hypolipidemic potential (Srinivasan, 2000). Curcumin of turmeric (Curcuma longa) and ginger have been documented to have pronounced hypolipidemic influence in a variety of experimental animal systems (Hussain 1993 and 1994).

From this point of view, the present study was designed to investigate the erythrocytic changes caused by hyperlipidemia in rats and to evaluate the possible protective effects of curcumin and ginger supplementation on these changes.

\section{MATERIALS AND METHODS}

Experimental animals:

Forty mature male albino rats weighing $120 \pm 10 \mathrm{~g}$ and averaging $4-5$ weeks old were purchased from laboratory animal unit of faculty of Veterinary Medicine, Benha University. They were housed in stainless steel cages and maintained at $25 \pm 2^{\circ} \mathrm{C}$ with a 12 hours light dark cycle and relative humidity $52 \%$. The animals were acclimatized to the laboratory conditions for 7 days before the experiment (Abdel Ghany, 2008). During this period, all animals were fed a balanced control basal diet according to Abdel-halim (2015) with ad libitum supply of fresh drinking water.

\subsection{Materials:}

A high fat diet (HFD) in which $45 \%$ of the calories were derived from corn oil was prepared according to Griffin et al., (2012). This diet was fed to the rats during the experimental period for experimental induction of hyperlipidemia.

Fresh curcumin and ginger rhizomes (air-dried rhizomes of the herb), purchased 
from local commercial sources, were milled mechanically into fine powder. The curcumin powder was incorporated into the HFD, replacing an equivalent amount of ground corn to give $0.2 \%$ curcumin supplemented high fat diet (Kempaiah and Srinivasoan, 2006) also ginger powder was incorporated into the HFD, replacing an equivalent amount of ground corn to give $4 \%$ ginger supplemented high fat diet (Akinyemi et al., 2016).

\subsection{Experimental design:}

The rats were assigned into 4 equal groups 10 rats in each:

Group 1: (Control group), rats were fed basal diet.

Group 2: (high-fat diet group), rats were fed HFD.

Group 3: (Curcumin supplemented HFD group), rats were fed high fat diet containing $0.2 \%$ curcumin powder.

Group 4: (Ginger supplemented HFD group), rats were fed high fat diet containing $4 \%$ ginger powder.

The experiment extended for two months.

\subsection{Blood sampling:}

At the end of experiment, two blood samples were collected from each rat from the retro orbital venous plexus. The first sample was collected in centrifuge tube without anticoagulant and placed in a slant position then centrifuged at 3000 r.p.m for 20 minutes to obtain the serum to be used in the biochemical analysis (determination of serum triacylglycerol, cholesterol, high density lipoprotein cholesterol and low-density lipoprotein cholesterol). The second blood sample was collected into a heparinized tube for determination of the erythrocyte osmotic fragility and phospholipids fractions in the rat erythrocyte membrane. The collected blood and serum samples were transferred (in an ice pack cooler) to the laboratory for analysis.

\subsection{Biochemical analysis:}

Serum TC, TAG and HDL-C were determined according to Young (2001) while LDL-C was determined according to Fried Wold et al., (1972). Osmotic fragility of erythrocyte was determined according to the method described by Faulkner and King (1970). Moreover, phospholipids concentrations in rat erythrocyte membrane (PC, PI, PE, PS) in which the blood was collected in heparinized tube $(1 \mathrm{ml}$ blood/ $\mathrm{ml}$ extract) in each tube for, preparation of cell membrane of RBCs ghosts were determined according to Michele et al., (2007). Extraction of lipids, membrane phospholipids and highpressure liquid chromatography procedures were determined according to Floch et al., (1957).

\subsection{Statistical analysis of data:}

Results are expressed as mean \pm standard error (SE). Differences between means in different groups were tested for significance using a One-way analysis of variance (ANOVA) followed by Duncan's test and $P$ value of 0.05 or less was considered significant (using the statistical analysis system, SPSS.

\section{RESULTS}

2.1. The effects of high fatty diet and dietary supplementation of ginger and curcumin on serum lipid profile (table, 2).

\subsubsection{Total cholesterol (TC)}

Rats fed HFD showed significant $(\mathrm{P}<0.05)$ increase in serum total cholesterol concentration $\quad(160.98 \pm 8.56 \mathrm{mg} / \mathrm{dl}) \quad$ as 
compared with the control group $(79.23 \pm 8.06$ $\mathrm{mg} / \mathrm{dl})$.

The serum total cholesterol concentration determined in rats fed on HFD containing ginger $(119.58 \pm 4.66 \mathrm{mg} / \mathrm{dl})$ was significantly $(\mathrm{P}<0.05)$ lower than that measured in HFD supplemented rats $(160.98$ $\pm 8.56 \mathrm{mg} / \mathrm{dl}$ ) but still significantly higher than that of the control.

The serum total cholesterol concentration determined in rats fed on HFD containing curcumin $(96.14 \pm 5.00 \mathrm{mg} / \mathrm{dl})$ was significantly $(\mathrm{P}<0.05)$ lower than that measured in HFD supplemented rats $(160.98 \pm 8.56 \mathrm{mg} / \mathrm{dl})$. Moreover, nonsignificant difference was observed between the curcumin supplemented group and the control group.

\subsubsection{Triacylglycerol:}

Rats fed HFD showed a significant $(\mathrm{P}<0.05)$ increase in serum TAG concentration $(119.51 \pm 8.47 \mathrm{mg} / \mathrm{dl})$ as compared with the control group $(87.96 \pm 2.36 \mathrm{mg} / \mathrm{dl})$.

Feeding HFD-curcumin and ginger supplemented diets significantly $(\mathrm{P}<0.05)$ decreased serum TAG concentrations (88.84 \pm 4.94 and $97.00 \pm 7.96$ respectively) as compared with feeding HFD (119.51 \pm 8.47 $\mathrm{mg} / \mathrm{dl})$. Moreover, non-significant differences were observed in serum TAG concentrations between HFD supplemented rats with curcumin or ginger or between these groups and the control.

\subsubsection{High density Lipoprotein cholesterol:}

Rats fed HFD showed non-significant $(\mathrm{P}>0.05)$ increase in serum HDL-C concentration $(34.24 \pm 1.22 \mathrm{mg} / \mathrm{dl})$ as compared with control group $(26.83 \pm 4.69 \mathrm{mg} / \mathrm{dl})$.

HFD-curcumin and ginger supplemented groups showed non-significant $(\mathrm{P}>0.05)$ increase in serum HDL-C concentrations
$(38.10 \pm 3.90$ and $36.90 \pm 1.25 \mathrm{mg} / \mathrm{dl}$, respectively) as compared with HFD supplemented group $(34.24 \pm 1.22 \mathrm{mg} / \mathrm{dl})$.

HFD- curcumin and ginger supplemented rats showed significant $(\mathrm{P}<0.05)$ increase in serum HDL-C concentration compared with control rats.

\subsubsection{Low density Lipoprotein cholesterol:}

Rats fed HFD showed a significant $(\mathrm{P}<0.05) \quad$ increase in serum LDL-C concentration $\quad(102.61 \pm 8.70 \mathrm{mg} / \mathrm{dl})$ as compared with the control group 34.81 \pm 3.99 $\mathrm{mg} / \mathrm{dl})$.

Feeding HFD-curcumin and ginger supplemented diets significantly $(\mathrm{P}<0.05)$ decreased serum LDL-C concentrations $(40.28 \pm 1.47$ and $63.28 \pm 2.34$ respectively) as compared with feeding HFD (102.61 \pm 8.70 $\mathrm{mg} / \mathrm{dl})$. Moreover, non-significant differences were observed in serum LDL-C concentrations between HFD supplemented rats with curcumin or ginger or between these groups and the control.

\subsection{Effect of high fat diet and dietary} supplementation of ginger and curcumin on erythrocyte membrane phospholipids:

Rats fed HFD showed highly significant $(\mathrm{P}<0.05)$ increase in concentrations of all measured types of phospholipids (phosphatidyl serine, phosphatidyl inositol, phosphatidyl ethanolamine and phosphatidyl choline) as compared with the control group.

Feeding curcumin and ginger supplemented HFD significantly $(\mathrm{P}<0.05)$ decreased the phospholipid concentrations as compared with HFD supplemented group but the recorded concentrations still significantly $(\mathrm{P}<0.05)$ higher than those of the control.

Also, appearance of un defined peak in high fat diet supplemented group with 
curcumin observed by chromatogram of phospholipids.

3.3. Effect of high fat diet and dietary supplementation of ginger and curcumin on osmotic fragility of erythrocytes (table 4):

There were non-significant $(\mathrm{P}>0.05)$ changes in percentage of hemolysis of erythrocytes at $0.1,0.2,0.3,0.6,0.7,0.8,0.9$ $\mathrm{NaCl}$ concentrations.

Rats fed HFD showed significant $(\mathrm{P}<$ $0.05)$ decrease of hemolysis $\%$ at $0.4 \%$ and $0.5 \% \mathrm{NaCl}$ concentrations $(0.97 \pm 0.57$ and 0 , respectively) as compared with the control group at the same concentrations $(34.36 \pm 1.78$ and $33.43 \pm 2.68$, respectively).

HFD- ginger supplemented rats showed significant $(\mathrm{P}<0.05)$ increase of hemolysis \%
$(7.43 \pm 0.88)$ at $0.4 \%$ Nacl concentration as compared with the HFD group $(0.97 \pm 0.57)$.

HFD- curcumin supplemented rats showed highly significant $(\mathrm{P}<0.05)$ increase of hemolysis \% $(14.54 \pm 1.65)$ at $0.4 \%$ Nacl concentration as compared with the HFD (0.97 \pm 0.57$)$.

HFD- ginger and curcumin supplemented rats showed highly significant $(\mathrm{P}<0.05)$ decrease of hemolysis $\%$ at $0.4 \%$ (7.43 \pm 0.88 and $14.54 \pm 1.65$, respectively) and $0.5 \%$ Nacl concentrations $(1.43 \pm 1.33$ and $1.15 \pm 0.18$, respectively) as compared with control group at the same concentrations (34.36 \pm 1.78 and $33.43 \pm 2.68$, respectively).

Table 1: The composition of various diets for rats.

\begin{tabular}{lcccc}
\hline $\begin{array}{l}\text { Ingredieants } \\
(\mathrm{g} / 100)\end{array}$ & $\begin{array}{l}\text { Control diet }) \\
(8 \mathrm{w})\end{array}$ & $\begin{array}{l}\text { High fat diet } \\
(8 \mathrm{w})\end{array}$ & $\begin{array}{l}\text { Ginger } \\
\text { supplemented } \\
\text { HFD }(8 \mathrm{w})\end{array}$ & $\begin{array}{l}\text { Curcumin }- \\
\text { supplemented }\end{array}$ \\
\hline HFD $(8 \mathrm{w})$
\end{tabular}




\begin{tabular}{|c|c|c|c|c|}
\hline Ginger & $===$ & $===$ & 4.0 & $===$ \\
\hline Curcumin & $===$ & $===$ & $===$ & 0.2 \\
\hline
\end{tabular}

Table (2): Effect of high fat diet and dietary supplementation of ginger and curcumin on serum lipid profile $(\mathrm{mg} / \mathrm{dL})($ means + S.E.)

\begin{tabular}{lllll} 
Parameters & TC & TAG & HDL-C & LDL-C \\
Groups & & & & \\
\hline Group I & $79.23^{\mathrm{c}} \pm 8.26$ & $87.96^{\mathrm{b}} \pm 2.36$ & $26.83^{\mathrm{b}} \pm 4.69$ & $34.81^{\mathrm{b}} \pm 3.99$ \\
Group II & $160.98 \pm^{\mathrm{a}} 8.56$ & $119.51^{\mathrm{a}} \pm 8.47$ & $34.24^{\mathrm{ab}} \pm 1.22$ & $102.61^{\mathrm{a}} \pm 8.70$ \\
Group III & $119.58^{\mathrm{b}} \pm 4.66$ & $97.00^{\mathrm{b}} \pm 7.96$ & $36.90^{\mathrm{a}} \pm 1.25$ & $63.28^{\mathrm{b}} \pm 2.34$ \\
Group IV & $96.14^{\mathrm{c}} \pm 5.00$ & $88.84^{\mathrm{b}} \pm 4.94$ & $38.10^{\mathrm{a}} \pm 3.90$ & $40.28^{\mathrm{b}} \pm 1.47$
\end{tabular}

Means with different letters in the same column are significantly different $(\mathrm{P}<0.05)$

Group I: control rats.

Group II: HFD rats.

Group III: HFD - ginger supplemented rats.

Group IV: HFD - curcumin supplemented rats. 
Table (3): Effect of high- fat diet and dietary supplementation of ginger and Curcumin on erythrocyte membrane phospholipids $(\mathrm{mg} / \mathrm{ml})$ (mean $\pm \mathrm{SE})$ :

\begin{tabular}{lclll}
\hline \multicolumn{1}{c}{ Parameters } & $\begin{array}{l}\text { Phosphat- } \\
\text { idylserine }\end{array}$ & $\begin{array}{l}\text { Phosphat- } \\
\text { idylinositol }\end{array}$ & $\begin{array}{l}\text { Phosphat- } \\
\text { idylethanolamine }\end{array}$ & $\begin{array}{l}\text { Phosphat- } \\
\text { idylcholine }\end{array}$ \\
\hline Group I & $3.35^{\mathrm{d}} \pm 0.50$ & $4.92^{\mathrm{c}} \pm 0.05$ & $4.11^{\mathrm{d}} \pm 0.03$ & $7.68^{\mathrm{d}} \pm 0.28$ \\
Group II & $4.08^{\mathrm{a}} \pm 0.17$ & $5.89^{\mathrm{a}} \pm 0.02$ & $4.67^{\mathrm{a}} \pm 0.02$ & $13.40^{\mathrm{a}} \pm 0.09$ \\
Group III & $3.83^{\mathrm{b}} \pm 0.02$ & $5.40^{\mathrm{b}} \pm 0.03$ & $4.50^{\mathrm{b}} \pm 0.01$ & $10.63^{\mathrm{b}} \pm 0.21$ \\
Group IV & $3.62^{\mathrm{c}} \pm 0.02$ & $5.47^{\mathrm{b}} \pm 0.03$ & $4.42^{\mathrm{c}} \pm 0.00$ & $8.87^{\mathrm{c}} \pm 0.19$ \\
\hline
\end{tabular}

Means with different letters in the same column are significantly different $(\mathrm{P}<0.05)$ 
Figure (1): Representative chromatogram of phospholipids standards

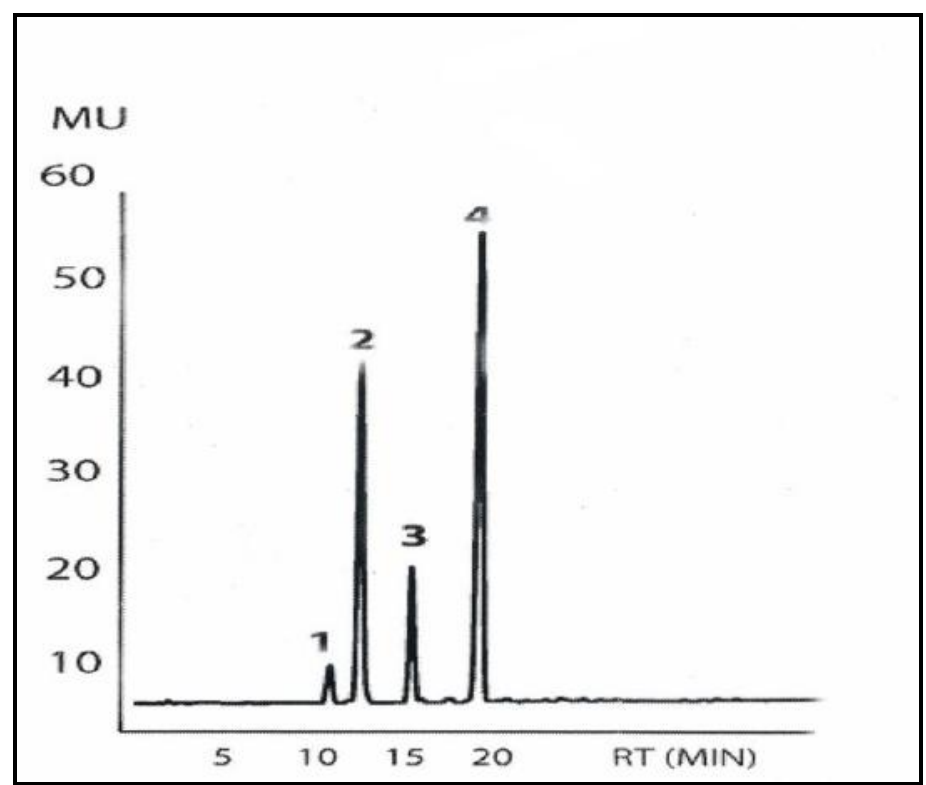

\begin{tabular}{|l|l|l|ll}
\hline 1 & PS & 2.21 & PS & : Phosphatidyl serine \\
\cline { 1 - 2 } 2 & PI & 5.16 & PI & : Phosphatidyl inositol \\
\cline { 1 - 2 } 3 & PE & 3.73 & PE & : Phosphatidyl ethanolamine \\
\cline { 1 - 2 } 4 & PC & 14.66 & PC & : Phosphatidyl choline \\
\hline
\end{tabular}

Figure (2): Representative chromatogram of phospholipids extracted from biological samples. 

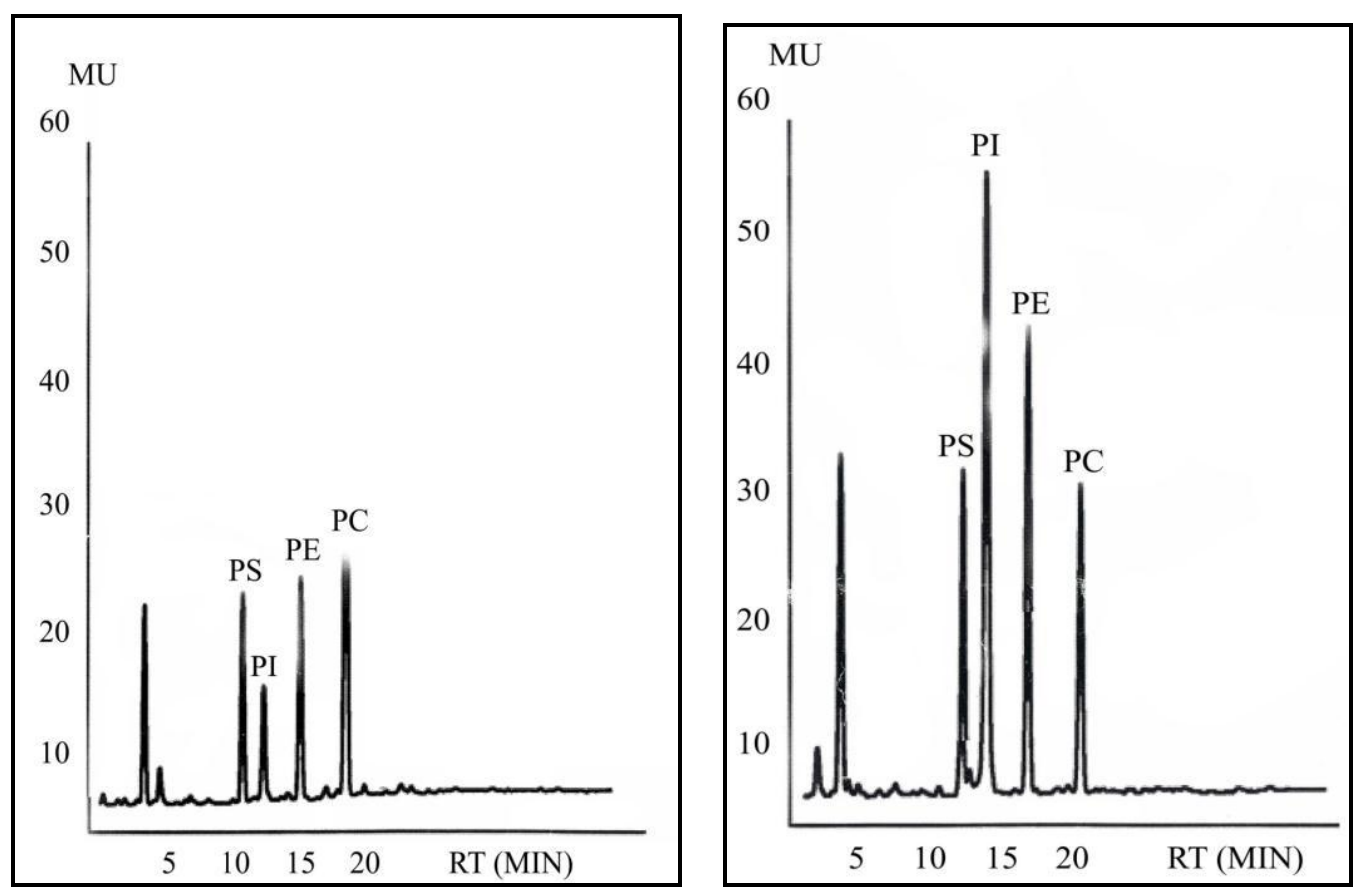

Ginger supplemented group Curcumin supplemented group
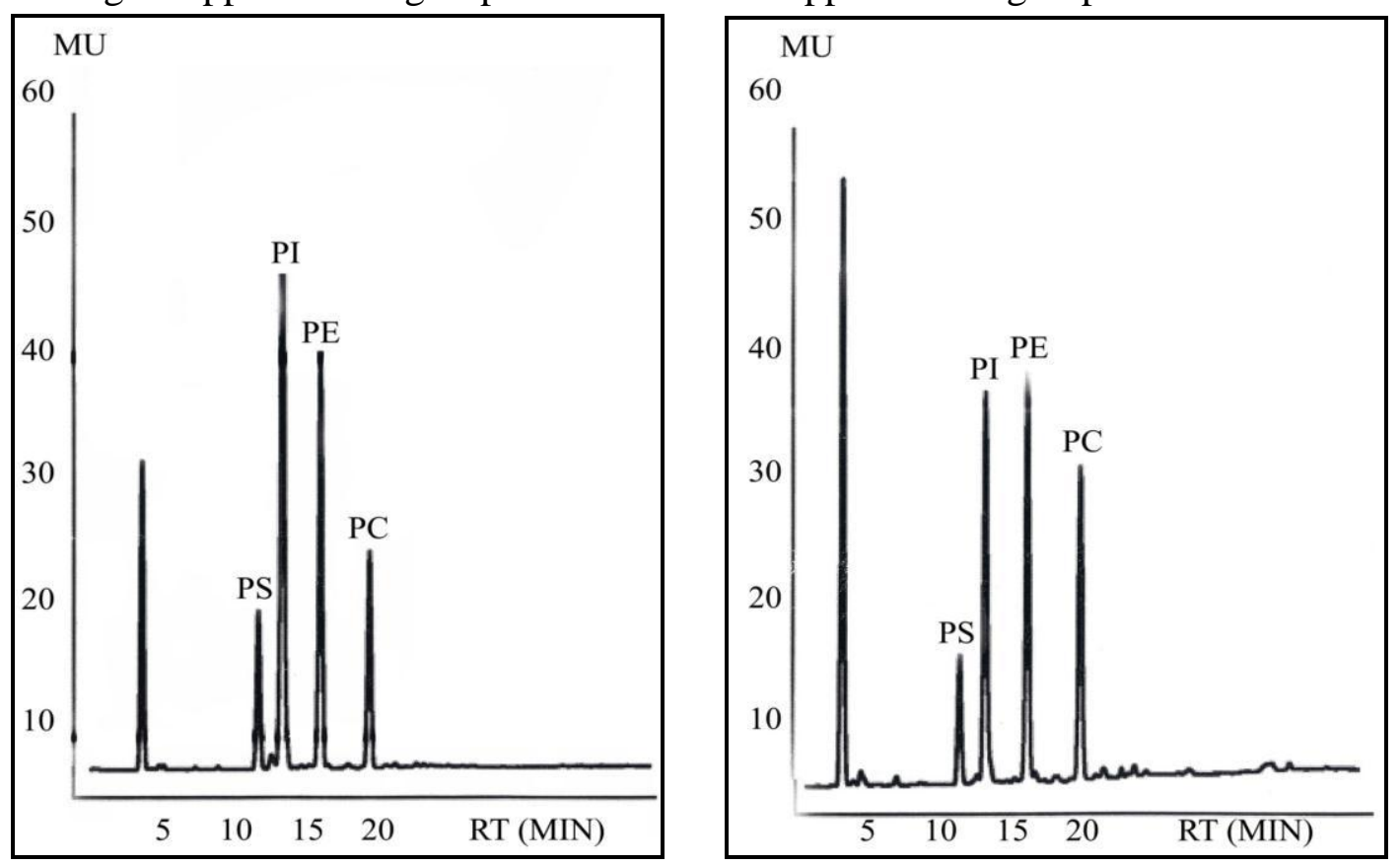

Figure (3): Effect of dietary supplementation of ginger and curcumin on osmotic fragility curve of erythrocytes in HFD fed rats (mean $\pm \mathrm{SE}$ ). 


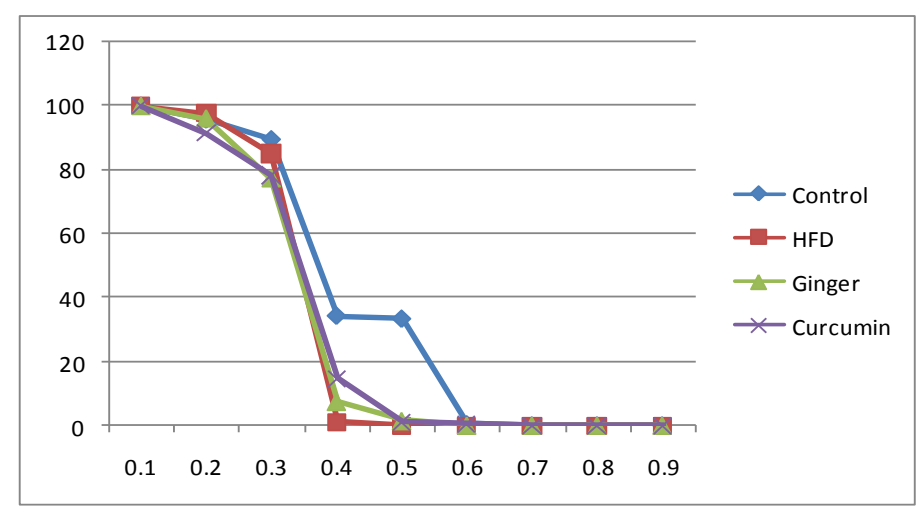

\section{DISCUSSION}

In the present study, rats fed HFD showed significantly increase in TG, TC and LDL-C concentrations and non-significant increase in HDL-C concentration when compared with the control rats. These results are in agreement with the results obtained by Abd El-Halim, (2015) who reported a marked significant increase in serum TG, TC and LDL-C levels and a non-significant change in HDL-C level after feeding rats with high fat diet.

Also, feeding HFD supplemented with ginger and curcumin resulted in marked significant decrease in TG, TC, LDL-C, and non-significant change in HDL-C concentrations when compared to HFD fed rats. Similar results were recorded by Abd ElGhaffar, (2014) after curcumin administration and by Akinyemi et al. (2016) after ginger administration to high fat diet fed rats. On the other hand, Mahluji et al. (2013) found that feeding rats with powdered ginger for two months,

significantly decreased TG and LDL but no significant changes were observed in total cholesterol and HDL levels in diabetic patients.

However, the mechanism by which curcumin and ginger lower plasma cholesterol could be due to increasing the removal of
VLDL by peripheral tissues (Harris, et al.,1984). Also, the hypolipidemic effect of curcumin and ginger was explained by Srinivasan and Sambaiah, (1991) who found that feeding ginger or curcumin to rats significantly elevated the activity of hepatic cholesterol 7- $\alpha$-hydroxylase, the rate limiting enzyme in bile acid biosynthesis, thereby stimulating cholesterol conversion to bile acids, resulting in elimination of cholesterol from the body, in addition, a pure constituent from turmeric and ginger was shown to inhibit cholesterol biosynthesis in a homogenate of rats' livers (Tanabe et al., 1993).

Similarly, Alizadeh et al., (2008) concluded that ginger can increase the hepatic cholesterol 7a-hydroxylase enzyme activity and the conversion of cholesterol into bile acids, resulting in reduced serum cholesterol concentration. Also, there are compounds in ginger that inhibit the biosynthesis

of cholesterol in the liver of rats beside the increasing effect of ginger on bile secretion, fecal excretion of phospholipids and reducing cholesterol levels (Sharma et al., 1991).

Regarding phospholipids, the results of the current study revealed that, HFD fed rats showed highly significant increase in membrane phospholipids (phosphatidyl 
choline, phosphatidyl serine, phosphatidyl ethanolamine and phosphatidyl inositol) as compared to the control rats. These results are in consistent with that of Pelliniemi, et al., (1976) who found phospholipids of rat erythrocytes analyzed during hyperlipidemic diet showed significant increase in erythrocyte phospholipids concentration after 3 weeks from induction of hyperlipidemia. In contrast to that, the studies of Bagdade and Ways, (1970) showed a decrease in cholesterol and phospholipid content of erythrocyte membrane in patient with exogenous (dietary) and endogenous (hepatic) types of hyperlipoproteinemia. An alternate possibility is that composition and function of plasma membrane may be affected by adaptive modifications of enzymatic machinery to long -term alterations in substrate levels (Henriquez et al., 1979, Tepperman and Tepperman, 1963).

Also, the results of the obtained study revealed that HFD rats showed highly significant increase in phosphatidyl choline as compared to control group. These results agree with that of Periago et al., (1990) who found changes induced by diet in the fatty acid composition of total phospholipids (highest levels of linoleic acid and lowest percentage of linolenic acid) observed in erythrocyte membranes PC with only minor changes in the fatty acid pattern of PE after feeding rats high fat diet.

In the present study, the significant increase of erythrocyte membrane phosphatidyl choline in HFD fed rats may be attributed to using corn oil as essential component in HFD of rats as corn oil contains relatively high concentration of (PUFA) (Valls, et al., 2003) so corn oil provides essential fatty acids mostly linoleic acid (Cedomila, et al., 2001).

Dietary ginger and curcumin are documented to protect the structural integrity of red blood cells under hyperchelesterolemic situation by preventing the alteration in the cholesterol: phospholipid ratio of their membranes affecting their structural integrity and thus corrected the increased osmotic fragility of erythrocytes (Kempaiah and Srinivasan, 2002).

A previous study conducted on mice showed that turmeric extract inhibited membrane phospholipid peroxidation in mice red blood cells and increased liver lipid metabolism, which indicates that turmeric extract has the ability to prevent the deposition of triacylglycerols with the liver (Asia et al., 1999).

Regarding hemolysis \% of erythrocytes expressed as hemoglobin released at different hypotonic concentrations of $\mathrm{NaCl}$ solution, erythrocyte osmotic fragility of HFD fed rats was significantly decreased compared to control normal rats. Thus, the osmotic fragility data suggested that red blood cells of HFD fed rats were relatively more resistant to osmotic lysis, but in HFD fed rats supplemented with ginger or curcumin the osmotic fragility partially and significantly restored toward normal level, also curcumin was more potent than ginger in this condition. Similar results obtained by Kempaih and Srinivassan, (2006) who found decreased fragility in HFD fed rats which was significantly restored toward normal by curcumin supplementation.

In the present study, feeding rats with HFD produced hyperlipidemia which significantly increased phospholipid concentration in erythrocyte membranes. Moreover, erythrocytes from rats under hypercholesterolemia, membrane fluidity was diminished while these cells featured C/P molar ratio (Kempaiah and Srinivasan, 2002). Contrary to this observation of mean cell fragility of erythrocytes of 
hypercholesterolemic rats being higher than normal animals, the same was somewhat lower than that of normal control indicating a slightly increased rigidity of high- fat fed rats here. such a decrease in mean cell fragility of erythrocytes, or in other words, a slightly increased rigidity of the erythrocytes in high fat fed rats (Cazana, et al., 1990).

HFD- ginger or curcumin supplemented rats showed significant $(\mathrm{P}<0.05)$ increase of hemolysis \% at $0.4 \% \mathrm{Nacl}$ concentration as compared with the HFD group. This is in agreement with the results of Kempaiah and Srinivasan, (2006) who concluded that, many spices (ginger and curcumin) displayed a protective influence on the erythrocyte integrity in the HFD induced hyperlipidemia. The obtained results may be attributed to that, ginger could lower lipid peroxide level in RBC membrane leading to a decreased susceptibility of RBC to hemolysis (El Kirdasy et al., 2015) and that, curcumin by itself did not cause either lipid peroxidation or hemolysis to RBCs and showed significant protection from lipid peroxidation and hemolysis (Niki, 1990).

We concluded that supplementation with ginger and curcumin to HFD rats resulted in significant decrease in serum lipid concentration, lowering membrane phospholipid and beneficially decreased mean cell fragility of erythrocytes thus restored the normality of erythrocyte fluidity in high fat diet fed rats.

\section{REFERENCES:}

Abd El-Ghaffar, M.M. (2014): Biochemical role of Curcumin, garlic and olive oil as oxidative ameliorative in hyperlipidemia rats. M.V.Sc. Thesis, Faculty of Veterinary Medicine. Benha University. PP: 60-79
Abd El-halim, R.A. (2015): A biochemical study on Retinol binding 4 in Relation to obesity. M.V. Sc. Thesis, Faculty of Veterinary Medicine. Zagazig University.

Abdel Ghany, A.A. (2008): Biochemical Effect of Angiotensin II Receptors Blockers and Angiotensin Converting Enzyme. Inhibitors on cholesterol Fed Rats. M.V.SC. Thesis, Faculty of Veterinary Medicine. Benha University.PP: 58.

Akinyemi, A.J.; Oboh, G.; Ademiluyi, A.O.; Boligon, A.A. and Athayde, M.L. (2016): Effect of two Ginger Varieties on Arginase Activity in Hypercholesterolemic Rats. J. Acupunct. Meridian Stud. 9(2): 80-87.

Alizadeh-Navaei, R.; Roozbeh, F.; Saravi, M.; Pouramir, M.; Jalali, F.and Moghadamnia, A.A. (2008): Investigation of the effect of ginger on the lipid levels. A double blind controlled clinical trial . Saudi .Med. J. 29:.1280- 1284.

Allen, H.G.; Allen,J.C.; Boyd,L.C.; AlstonMills,B.P. and Fenner, G.P.(2006): Determination of membrane lipid differences in insulin resistant diabetes mellitus type 2 in whites and blacks. Nutr.22:1096-1102.

Andrzej, K.; Przemyslaw, M.; Piotr, K.; Stanislawa, S.K.; Boleslaw, F. and Marta, S. Z. (2002): The influence of hypomagnesaemia on erythrocyte antioxidant enzyme defence system in mice. Biometal 16:349-357.

Asia, A.; Nakagawa, K. and Miyazawa, T. (1999): Antioxidative effects of turmeric, rosemary and Capsicum extracts on membrane phospholipid 
peroxidation and liver lipid metabolism in mice. Biosci .Biotechnol . Biochem.,63: 2118-22.

Badior, K.E. and Casey, J.R. (2018): Molecular mechanism for the red blood cell senescence clock. IUBMB Life, 70 (1): 32-40.

Bagdade, J.D. and Ways, P.O. (1970): Erythrocyte membrane lipid composition in exogenous and endogenous hypertriglyceridemia, J. Lab. Clin.Med., 75, 53.

Barenholz,Y. (2002): Cholesterol and other membrane active sterols: from membrane evolution to "rafts" . Prog. Lipid Res. 41:1-5.

Barenholz, Y. and Thompson, T.E. (1999): Sphingomyelin: biophysical aspects. Chem. Phys. Lipids 102:29-34.

Cazana, F.J.D., Puyol, M.R., Caballero, J.P., Jimenez, A.J., and Duarte, A.M. (1990): Effect of dietary hyperlipidemia-hypercholesterolemia on rat erythrocytes.Int. J. Vitam. Nutr. Res., 60: 393-397.

Cedomila, M.; Robert, D; Marin, T.; Jasminka, G.; Mira, C.; Biserka, R. and Zlatko, C.(2001): "Effect of olive oil and corn oil-Enriched Diets on the tissue mineral content in Mice," Biol. Trace Element Res.. 82 (1-3): 201-210.

Elkirdasy, A.; Shousha, S.; alrohaimi, A. H. and Arshad, M. F. (2015): Hematological and Immunobiochemical study of green tea and ginger extracts in experimentally induced diabetic rabbits. Acta. Poloniae Pharmaceutica ñ Drug Res., 72 (3): 497-506.

Faulkner, W. R. and King, J. W. (1970): Manual of Clinical Laboratory procedures. Published by the Chemical Rubber Company, Cleveland, Ohio, $354 \mathrm{pp}$.

Folch J.; Lees, M. and Sloane Stanley, G. H. (1957): A simple method or the isolation and purification of total lipids from animal tissues. J. Biol. Chem., 226, 497-509.

Friendwold, W.L; Levy, R.I. and Fredrickson, D.S. (1972): Estimation of LDLcholesterol in plasma a without use of the preparative ultracentrifuge clin.chem., 18: 499.

Griffin, T.M.; Heubner, J. L.; Kraus, V.B; Yan, Z. and Guilak, F. (2012): Induction of Osteoarthritis and metabolic inflameation by a very highfat diet in mice' Rheum, 64 (2) 443-53.

Hamai, C.; Yang, T.; Kataoka, S.; Cremer, P.S. and Musser, S.M. (2006): Effect of average phospholipid curvature on supported bilayer formation on glass by vesicle fusion. Biophys J. 90:12411248.

Harris, W.S.; Conner, W.E.; Illigworth, D.R. and Foster, D.M. (1984): The mechanism of the hypotriglyceridaemic effect of dietary omega-3 fatty acids in man. Clin.Res., 32, 560 Abstract.

Harris, F.M.; Smith, S.K. and Bell, J.D. (2001): Physical properties of erythrocyte ghosts that determine susceptibility to secretory phospholipase A2. J. Biol. Chem. 276: 22722-22731.

Hazel, J.R. and Williams, E.E. (1990): The role of alterations in membrane lipid composition in enabling physiological adaptation of organisms to their 
physical environment. Prog. Lipid Res. 29:167-227.

Henriquez, D.S.; Tepperman, H.M. and Tepperman, J. (1979): Effects of high glucose and high-fat diets on Concanaval in A binding to rat liver plasma membranes and on the amount and pattern of their glycoproein carbohydrates, J. Lipid Res., 20 .624.

Himbert, S.; Alsop, R. J.; Rose, M.; Hertz, J.; Dhaliwal, A. and Moran-Mirabal, J. M. (2017): The molecular structure of human red blood cell membranes from highly oriented solid supported multilamellar membranes. Scientific reports, $7: 39661$.

Hussain, M.S. and Chandrasekhara, N. (1993): Influence of curcumin and capsaicin on chdesterol gall stone induction in hamsters and mice. Nutr. Res., 13: 349-57.

Hussain, M.S. and Chandrasekhara, N. (1994a): Biliary proteins from hepatic bile of rats fed curcumin or capsaicin inhibit cholesterol crystal nucleation in supersaturated model bile. Indian J. Biochem.Biophys., 31: 407-412.

Hussain, M.S. and Chandrasekhara, N. (1994b): Effect of curcumin and capsaicin on the regression of preestablished cholesterol gallstones in mice.Nutr. Res., 14: 1561-1574.

Kempaiah, R.K. and Srinivasan, K. (2002): integrity of erythrocytes of hypercholesterolemic rats during spice treatment. Mol. Cell Biochem., 236 :155-61.

Kempaiah, R.K. and Srinivasan, K. (2006): Benificial influence of dietary curcumin, capsaicin and garlic on erythrocyte integrity in high-fat fed rats. J. Nutrit. Biochem., 17:471- 478.

Koay, E.S.C. and Walmsley, N. (1999): Plasma lipids and lipoproteins. In:Koay, E.S.C. and Walmsley, N. (eds) A primer of chemical pathology. World Scientific, Singapore, PP. 191211.

Mahluji,S.; Attari,V.E.; Mobasseri, M.;Payahoo, L.; Ostadrahimi, A. and Golzari,S .E.(2013): Effects of ginger (Zingiber officinale) on plasma glucose level , HbA1c and insulin sensitivity in type 2 diabetic patients. Int. J. Food Sci. Nutr. 64: p.682 -686.

Michele, G.; Domenico, M.; Gigliola, M.; Laura, D.; Manuela, N.; Bruno, B. and Angela, M. R. (2007): Plasma, red blood cells phospholipids and clinical evaluation after long chain omega-3 supplementation in children with attention deficient hyperactivity disorder (ADHD), Nutr. Neuroscience, 10 (1/2): 1-9.

Niki, E. (1990): Free radical initiators as source of water or lipid soluble peroxyl radicals, Methods Enzymol. 186. P.100-108.

Pellinieml, T.T.; Viikari, J. and Nieminen, L. (1976): Effect of Hyperlipidemic Diet and Clofibrate Treatment on Rat Erythrocyte Lipids. J. Haematol., 17; 117-122.

Periago, J.L.; Suarez, M.D. and Pita, M.L. (1990): Effect of dietary olive oil, corn oil and medium-chain triglycerides on the lipid composition of rat red blood cell membrane. J. Nutr., 120: 986-994.

Sharma, I.; Gusain, D. and Dixit, V. P.(1991): Hypolipidaemic and antiatherosclerotic 
effects of plumbagim in rabbits. Indian J. Physiol. Pharmacol. 35:p.10-14.

Srinivasan, K. and Sambaiah, K. (1991): The effect of spices on cholesterol. 7-alpha hydroxylase activity and on serum and hepatic cholesterol levels in the rat. International J. of vit. and Nutr. Res., 61(4), 364-369.

Srinivasan, K. (2000): Spices- valued for more than taste and flavour of foods. In: De $\mathrm{AK}$, editor. Recent trends in spices and medicinal plants research. New Delhi: Associated Publishing Co; p.31-8.

Tanabe, M.; Chen, Y.; Saitok, and Kano, Y. (1993): Cholesterol biosynthesis inhibitory component from zingiber officinable roscoe. Chem. Pharm. Bull., 41: 710-713.

Tepperman, H.M. and Tepperman, J.(1963):, on the response of hepatic glucose-6phosphate dehydrogenase activity to changes in diet Composition and food intake pattern, Adv. Enzyme Regul., 1 .121 .

Valls, M.G.V.; Mun, P.; Saez, G.T. and Cabo, J.R. (2003): "Effect of corn oil and vitamin $\mathrm{E}$ on the oxidative status of Adipose tissues and liver in Rat" Food Chem.Vol. 81, No. 2, May, PP. 281-286. Doi: 10.1016/s0308-8146(02) 00425-9.

Williams, E.E. (1998): Membrane lipids: what membrane physical properties are conserved during physiochemicallyinduced membrane restructuring. Am. Zool. 38:280-290.

Young, D.S. (2001): Effects of disease on clinical lab. Tests, $4^{\text {th }}$ ed., AACC.

Zicha, J.; Kunes, J and Devynck, M.A. (1999): Abnormalities of membrane function and lipid metabolism in hypertension. Am. J. Hypertens. 12 (3): 315-331. 